First-principles calculations of anharmonic and deuteration effects on the photophysical properties of polyacenes and porphyrinoids

\author{
Valiev, R. R.
}

2020-10-21

Valiev, R R, Nasibullin , R T , Cherepanov , V N , Baryshnikov, G, Sundholm , D , Ågren , $H$, Minaev , B F \& Kurten , T 2020 , ' First-principles calculations of anharmonic and deuteration effects on the photophysical properties of polyacenes and porphyrinoids ', Physical Chemistry Chemical Physics , vol. 22 , no. 39 , pp. 22314-22323 . https://doi.org/10.1039/d0cp03231j

http://hdl.handle.net/10138/334017

https://doi.org/10.1039/d0cp03231j

unspecified

acceptedVersion

Downloaded from Helda, University of Helsinki institutional repository.

This is an electronic reprint of the original article.

This reprint may differ from the original in pagination and typographic detail.

Please cite the original version. 


\title{
First-principles calculations of anharmonic and deuteration effects on photophysical properties of polyacenes and porphyrinoids
}

R. R. Valiev, ${ }^{\mathrm{a}, \mathrm{b}}$ R. T. Nasibullin, ${ }^{\mathrm{b}}$ V. N .Cherepanov, ${ }^{\mathrm{b}}$ G. V. Baryshnikov, ${ }^{\mathrm{c}, \mathrm{d}}$, D.

Sundholm, ${ }^{\mathrm{a}}$ H. Ågren ${ }^{\mathrm{c}}$, B. F Minaev ${ }^{\mathrm{c}, \mathrm{d}}$ and T. Kurtén ${ }^{\mathrm{a}}$

${ }^{a}$ University of Helsinki, Department of Chemistry, P.O. Box 55

(A.I. Virtanens plats 1), FIN-00014 University of Helsinki, Finland

${ }^{b}$ Tomsk State University, 36 Lenin Avenue, Tomsk, Russia

${ }^{c}$ Division of Theoretical Chemistry and Biology, School of Biotechnology,

KTH Royal Institute of Technology, 10691 Stockholm, Sweden.

${ }^{d}$ Bohdan Khmelnitsy National University, Cherkasy, 18031, Ukraine

\begin{abstract}
A new method for calculating internal conversion rate constants $\left(\underline{k}_{I C}\right)$, including anharmonic effects and using the Lagrangian multiplier technique, is proposed. The deuteration effect on $\underline{k}_{I C}$ was investigated for naphthalene, antracene, free-base porphine $\left(\mathrm{H}_{2} \mathrm{P}\right)$ and tetraphenylporpyirn $\left(\mathrm{H}_{2} \mathrm{TPP}\right)$. The results show that anharmonic effects are important when calculating $\underline{k}_{I C}$ for transitions between electronic states that are energetically separated $(\Delta E)$ by more than $20000-25000$ $\mathrm{cm}^{-1}$. Anharmonic effects are also important when $\Delta E<20000-25000 \mathrm{~cm}^{-1}$ and when the accepting modes are $\mathrm{X}-\mathrm{H}$ stretching vibrations with a frequency larger than $2000 \mathrm{~cm}^{-1}$. The calculations show that there is a mixture between the $S_{1}$ and $S_{2}$ states of napthtalene induced by non-adiabatic interactions. The non-adiabatic interaction matrix element between the $S_{1}$ and $S_{2}$ states is $250 \mathrm{~cm}^{-1}$ and $50 \mathrm{~cm}^{-1}$ for the normal and fully deuterated naphthalene structure and this difference significantly affects the estimated fluorescence quantum yield. Besides aromatic hydrocarbons, $\left(\mathrm{H}_{2} \mathrm{P}\right)$ and $\left(\mathrm{H}_{2} \mathrm{TPP}\right)$, the $\underline{k}_{I C}$ rate constant is also calculated for pyrometene (PM567) and tetraoxa[8]circulene (4B) with a detailed analysis of the effect of the vibrational anharmonicity.
\end{abstract}




\section{Introduction}

Accurate and detailed information about molecular photophysical properties is necessary in many applications like development of optical devices and organic light emitting diodes (OLEDs) [1-3], dye-based lasers [4-6], upconverting nanoparticles [7-9], bioimaging and photodynamic therapy devices [10-12]. Molecular photophysical properties are also very important for elucidating chemical processes in the lower atmosphere and interstellar clouds, like photolysis of molecules in gases [13-15], smog and aerosol particle formation [16, 17]. The key parameters of photophysical properties are the rate constants for radiative and non-radiative transitions [18-21]. Knowledge about them gives the opportunity to estimate the quantum yield of photophysical and photochemical processes. For example, the fluorescence quantum yield $\left(\varphi_{f l}\right)$ can be estimated using the simple formula $\varphi_{f l}=k_{r} /\left(k_{n r}+k_{r}\right)$, where $k_{r}$ is the rate constant of the radiative transition and $k_{n r}$ is the total rate constant of the non-radiative transitions between initial and final electronic states [21]. At low molecular concentrations when the intermolecular interactions are very weak, a simple expression holds: $k_{n r}=k_{I C}+k_{\text {ISC }}$, where $k_{I C}$ is internal conversion (IC) rate constant between electronic states with the same spin multiplicity and $k_{\text {ISC }}$ is the intersystem crossing (ISC) rate constant between electronic states with different spin multiplicities [21]. The $k_{I C}$ and $k_{\text {ISC }}$ rate constants can be calculated using various softwares at different levels of theory [19, 20, 22-27]. The most popular method is based on correlation functions for estimating Franck-Condon contributions [22-25]. The problem of the summation of final states is then converted into time-domain integration using Fourier transformation. Another approach for calculating $k_{I C}$ and $k_{\text {ISC }}$ is to explicitly consider final states with selected accepting modes [20, 26-29]. Calculating the $k_{\text {ISC }}$ constant is generally not a very difficult task. The $k_{I S C}$ value can even be estimated using the Marcus's theory [30, 31]. However, calculating $k_{I C}$ is more difficult, since the non-adiabatic coupling interaction matrix element (NACME) between the electronic states of the same spin multiplicity is needed. 
Moreover, large energy gaps between the two lowest singlet states $\left(\mathrm{S}_{1}\right.$ and $\left.\mathrm{S}_{0}\right)$ are challenging for IC theory, because anharmonic effects may be significant [21].

Recently, we have developed a first principle method for calculating $k_{I C}$ and $k_{\text {ISC }}$, which has been successfully applied to a number of organic and organometallic molecules for which the experimental data were available [27, 32]. We obtained rate constants in a good agreement with experimental data when the Franck-Condon and the adiabatic approximations hold. Some exceptions were found for polyacenes and free-base porphyrin $\left(\mathrm{H}_{2} \mathrm{P}\right)$ [27]. $\mathrm{H}_{2} \mathrm{P}$ is a rigid molecule possessing a very small Stokes shift $\left(<100 \mathrm{~cm}^{-1}\right)$, which implies that the HuangRhys factors are small [27]. We suggested that the non-adiabatic interaction induced mixing between the first $\left(\mathrm{S}_{1}\right)$ and second $\left(\mathrm{S}_{2}\right)$ excited singlet electronic states is the main reason for the deviation of the calculated rate constants from the experimental ones. We recently extended our approach by additionally accounting for Herzberg-Teller effects using fitting curves [26]. The extended method was successfully used in calculations of photophysical properties of $\mathrm{H}_{2} \mathrm{P}$, showing that the $k_{I C}$ rate constant of $\mathrm{H}_{2} \mathrm{P}$ can be accurately estimated in the Herzberg-Teller approximation. In our recent studies, we considered molecules that fluoresce with energies below $25000 \mathrm{~cm}^{-1}[26,27]$. The calculations showed that $k_{I C}$ is small when the energy difference between $S_{1}$ and $S_{0}$ is larger than $20000 \mathrm{~cm}^{-1}$, implying that the IC rate is much slower than the ISC rate and the rate of radiative processes [28]. In the harmonic approximation, $k_{\text {IC }}$ decreases rapidly with increasing energy difference when the gap exceeds $25000 \mathrm{~cm}^{-1}[26,27]$. Large energy gaps imply that molecular vibrations with high quantum numbers and consequently with significant anharmonicity are involved in the non-radiative transition. In calculations of $k_{\text {IC }}$ rates, Plotnikov studied anharmonic effects by considering only vibrational modes involving $\mathrm{X}-\mathrm{H}$ bonds ( $\mathrm{X}=\mathrm{C}, \mathrm{O}$ and $\mathrm{N}$ atoms), because they have the largest anharmonicities [28]. The problems to estimate $k_{\text {IC }}$ for transitions whose energies exceed $25000 \mathrm{~cm}^{-1}$ have been discussed by Makshantsev [33, 34]. Accurate $k_{I C}$ rate constants for benzene, naphthalene, antracene, and other 
molecules whose transition energies are larger than $25000 \mathrm{~cm}^{-1}$ can be calculated only by considering anharmonic effects [35].

In this work, we have implemented methods to calculate anharmonic effects into our algorithm to calculate rate constants for non-radiative transitions [26, 27]. We have also implemented an algorithm to calculate Franck-Condon factors using the method of Lagrange multipliers [21]. The modified methods are used for calculating $k_{I C}$ for benzene, naphthalene and anthracene for which the anharmonicity plays a crucial role. The method has also been used for calculating $k_{I C}$ for free-base porphyrin $\left(\mathrm{H}_{2} \mathrm{P}\right)$, free-base tetraphenylporphyrin $\left(\mathrm{H}_{2} \mathrm{TPP}\right)$, pyrometene (PM567) and tetraoxa[8]circulene (4B) (Figure 1), which emit light in the different areas of the electromagnetic spectrum [26, 27]. We also compare the rate constants and quantum yields with values obtained in previous calculations. Rate constants are calculated for perdeuterated naphthalene, anthracene, $\mathrm{H}_{2} \mathrm{P}$, and $\mathrm{H}_{2} \mathrm{TPP}\left(\mathrm{D}_{2} \mathrm{P}\right.$, and $\left.\mathrm{D}_{2} \mathrm{TPP}\right)$ in order to investigate the influence of the deuteration on their photophysical properties. We have also estimated the non-adiabatic coupling induced mixing between the $S_{1}$ and $S_{2}$ states of the naphthalene and anthracene species.

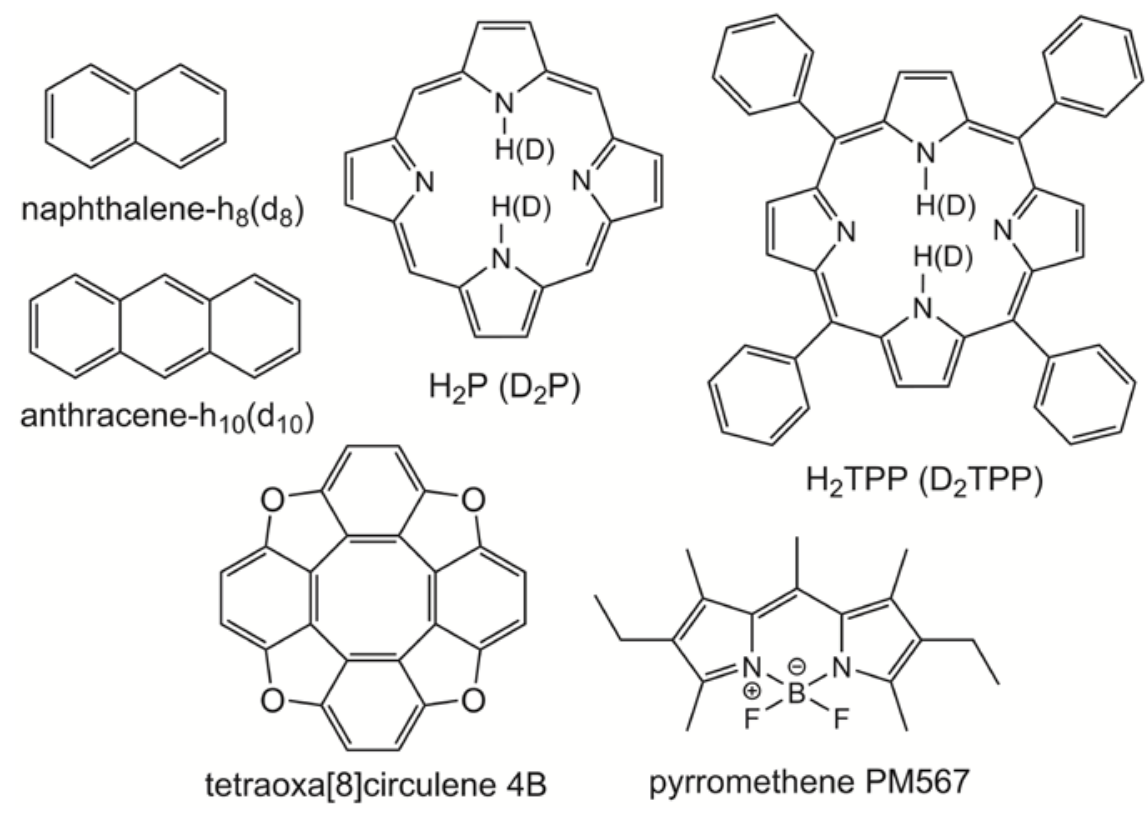

Figure 1. The molecular structures of the studied molecules. 


\section{Theory}

\subsection{The general formula}

Calculations of non-radiative rate constants for transitions between electronic states is difficult due to the many factors that influence the mechanisms of the physical processes. Non-radiative electronic transitions must fulfil many conditions [21]. First of all, they must be irreversible [21], which can occur in the limit of high density of states when the Bixon-Jortner model [29] is applicable or in the intermediate case $[21,28]$. The statistic limitation corresponds to a large density of final states. In the polyatomic molecules, the density of final states is large when the energy gap amounts to several eV [21]. However, all final states are not effective or accepting in non-radiative processes. Some states accept energy with high probability in non-radiative processes [21]. The density of states of these so called effective states is important for non-radiative electronic transitions. For small density of states, the non-radiative electronic transitions have resonance character and the broadening of the final states can be described by a Lorentzian function, whose width corresponds to the lifetime of the vibration relaxation [21, 28]. Thus, the irreversibility of non-radiative electronic transitions is due to small lifetimes of the effective states. The intermediate case is more general and the expression of $k_{n r}$ can be expressed as [21, 28]:

$$
k_{\mathrm{nr}}=\sum_{n}\left|V_{i 0, f n}\right|^{2} \Gamma_{f n}\left[\Delta_{i f}^{2}+\frac{\Gamma_{f n}^{2}}{4}\right]^{-1}
$$

where $i$ is the initial electronic state, $f$ is the final electronic state, $n$ is a vibrational level of the final state, $\Gamma_{f n}$ is the relaxation width of the vibrational level $\mid f n>$, $\Delta_{i f}=\left|E_{i 0}-E_{f n}\right|$ is the energy difference between the initial and final vibrational states, and $V_{i 0, \text { fn }}$ is the matrix element of the perturbation operator. Only the lowest vibrational level of the initial state is considered. Actually, temperature effects can be also accounted for by using Eq. (1). However, in many of the applications discussed in the introduction, it is enough to consider the low-temperature condition of the electronic transitions. The perturbation operator is the spin-orbit 
coupling interaction for ISC transitions and the non-adiabatic coupling interaction for IC processes. Eq. (1) written in atomic units holds at ambient temperatures ( $\mathrm{T} \leq 300 \mathrm{~K}$ ) when $k_{\mathrm{nr}}<<\Gamma_{f n}$. When the $k_{\mathrm{nr}}<<\Gamma_{f n}$ condition does not hold, then $k_{\mathrm{nr}} \sim 0.5 \cdot \Gamma_{f n}$ applies [28].

In general, the energy of the excited electronic state is transferred into the effective states of the accepting vibrational modes. The energy is then converted into other vibrational modes of molecule or into vibrational modes of the solvent or of other surrounding molecules resulting in irreversibility of the non-radiative electronic transition.

$\Gamma_{f n}$ depends on the molecular structure and the $n$ value[36, 37]. However, the order of magnitude of $k_{n r}$ is nearly independent of $\Gamma_{f n}$ when $10^{12} \mathrm{~s}^{-1}<\Gamma_{f n}<10^{14} \mathrm{~s}^{-1}$ holds [28]. The effect of different spectral line shapes and widths of the final state has recently been investigated [25], where they showed that the broadening profile of the final state is very important. For example, Lorentzian broadening influences strongly the calculated $k_{n r}$ value when using the autocorrelation function approach. Although the choice of the spectral line shape function of the final state is still under debate, the Lorentzian shape function is in general a good choice. Since it is difficult to calculate $\Gamma_{f n}$, it is better to estimate its value from experimental data [25]. A typical value for $\Gamma_{f n}$ is $\sim 10^{14} \mathrm{~s}^{-1}$ [28], which we adopt in this work.

The following approximations have previously been used in our calculations of the rate constants of non-radiative transitions:

1) The harmonic approximation, where the harmonic oscillator model is used for the initial and final vibrational states.

2) The adiabatic approximation for the initial and final electronic states is used. 
3) The linear coupling model, where the vibrational frequencies of the initial and final states are the same and the displacement of the equilibrium position is considered only in the calculation of the matrix elements of the Franck-Condon and Herzberg-Teller factors. Here, we introduce the $y$ parameters, which reflect the displacement of the equilibrium position of each harmonic oscillator. The linear coupling model is valid, when the Duschinsky effect is small.

4) In the Herzberg-Teller approximation, the matrix elements of the perturbation operator are expanded along the normal coordinates. The zeroth-order and first-order terms are considered.

The rate constants in Eq. (1) for the different physical processes can then be written as [26]:

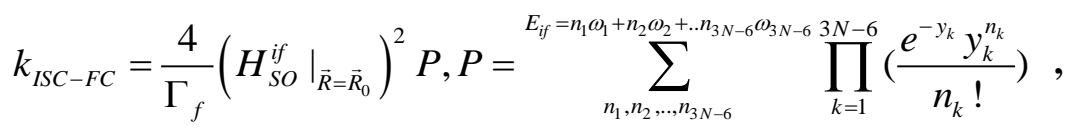

$$
\begin{aligned}
& k_{I S C-H T}=\sum_{j=1}\left(t_{j} W_{j} \sqrt{P_{j}}\right)^{2}, P_{j}=\sum_{n_{1}, n_{2}, \ldots, n_{3 N-6}}^{E_{i f}-n_{j} \omega_{j}=n_{1} \omega_{1}+n_{2} \omega_{2}+\ldots n_{3 N-6} \omega_{3 N-6}} \prod_{\substack{k=1 \\
k \neq j}}^{3 N-6}\left(\frac{e^{-y_{k}} y_{k}^{n_{k}}}{n_{k} !}\right), \\
& \left.k_{I C-F C}=\frac{4}{\Gamma_{f}} \sum_{j=1}\left(d_{j} \cdot b_{j} \sqrt{P_{j}}\right)^{2}, P_{j}=\sum_{n_{1}, n_{2}, \ldots, n_{3 N-6}}^{E_{i f}-n_{j} \omega_{j}=n_{1} \omega_{1}+n_{2} \omega_{2}+\cdots n_{3-} \omega_{3 N-63 N-6}} \prod_{\substack{k=1 \\
k \neq j}}^{\left(\frac{y^{-y_{k}}}{n_{k}} y_{k} !\right.}\right),
\end{aligned}
$$

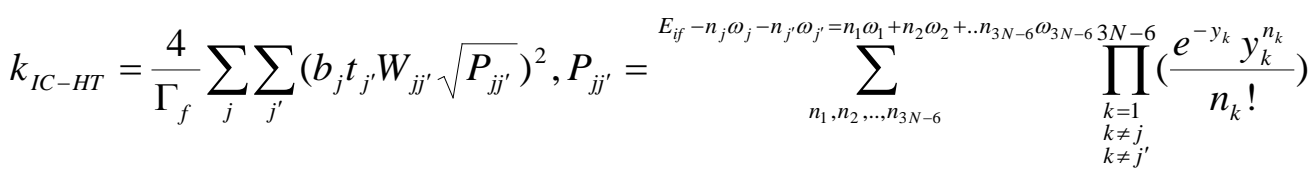

where,

$$
\begin{gathered}
W_{j j^{\prime}}=-\sum_{v} \sum_{q} \sum_{v^{\prime}} \sum_{q^{\prime}}<\frac{\varphi_{i}(\vec{r}, 5, \vec{R}) \partial^{2} \varphi_{f}(\vec{r}, 5, \vec{R})}{\partial R_{v q} R_{v q^{\prime}}}>\left.\right|_{R=R_{0}} M_{v}^{-1 / 2} M_{v^{\prime}}^{-1 / 2} L_{v q j} L_{v^{\prime} q^{\prime} j^{\prime}} \\
D=-\sum_{v} \sum_{q}\left(2 M_{v}\right)^{-1}<\varphi_{i}(\vec{r}, \bar{s}, \vec{R})\left|\frac{\partial^{2}}{\partial R_{v q}^{2}}\right| \varphi_{f}(\vec{r}, \bar{s}, \vec{R})>\left.\right|_{\vec{R}=\vec{R}_{0}}, \\
d_{j}=-\sum_{v} \sum_{q} M_{v}^{-1 / 2} L_{v q j}<\varphi_{i}(\vec{r}, 5, \vec{R}) \frac{\partial \varphi_{f}(\vec{r}, 5, \vec{R})}{\partial R_{v q}}>\left.\right|_{\vec{R}=\bar{R}_{0}}, \\
t_{j}=<\chi_{i 0_{j}}\left(Q_{j}\right)\left|Q_{j}\right| \chi_{f n_{j}}\left(Q_{j}\right)>=\left[\frac{1}{2 \omega_{j} n_{j} !}\left(n_{j}+y_{j}\right)^{2} \cdot e^{-y_{j}} \cdot y_{j}^{n_{j}-1}\right]^{1 / 2},
\end{gathered}
$$




$$
\begin{aligned}
b_{j}=<\chi_{i 0_{j}}\left(Q_{j}\right)\left|\frac{\partial}{\partial Q_{j}}\right| \chi_{f n_{j}}\left(Q_{j}\right)>=\left[\frac{1}{2 n_{j} !} \omega_{j}\left(n_{j}-y_{j}\right)^{2} \cdot e^{-y_{j}} \cdot y_{j}^{n_{j}-1}\right]^{1 / 2}, \\
y_{j}=\frac{1}{2}\left(\omega_{j}\right) \cdot\left|Q^{f}{ }_{0_{j}}-Q_{0_{j}}^{i}\right|^{2} \\
W_{j}=\left[\sum_{v} \sum_{q}\left(\left.\frac{\partial\left(H_{S O}^{i f}\right)}{\partial R_{v q}}\right|_{R=R_{0}} M_{v}^{-1 / 2} L_{v q j}\right] .\right.
\end{aligned}
$$

Here, $\left\langle\varphi_{i}(\vec{r}, s, \vec{R}) \frac{\partial \varphi_{f}(\vec{r}, s, \vec{R})}{\partial R_{v q}}>\left.\right|_{R=R_{0}}\right.$ and $\left\langle\frac{\varphi_{i}(r, s, \vec{R}) \partial^{2} \varphi_{f}(r, s, \vec{R})}{\partial R_{v q} R_{v^{\prime} q^{\prime}}}>\left.\right|_{R_{R}=\vec{R}_{0}}\right.$ are the nonadiabatic coupling matrix elements (NACMEs) of the first and second order, respectively. $M_{v}$ is the mass of the $v^{\text {th }}$ atom, $L_{v q j}$ are coefficients of the linear relation between the Cartesian $(R)$ and the normal coordinates $(Q)$ : $R_{v q}-R_{0 v q}=M_{v}^{-1 / 2} L_{v q j} Q_{j}$. The $t_{j}$ and $b_{j}$ integrals are the Herzberg-Teller and nonadiabatic factors, respectively. The $y_{j}$ parameter is the Huang-Rhys factor of the $j^{\text {th }}$ accepting mode. $H_{S O}^{i f}$ is a matrix element of the spin-orbit coupling (SOC) interaction. The $E_{\text {if }}$ value is the energy gap between the initial and the final states, and $n_{j}$ and $\omega_{j}$ are the excitation quantum number and the frequency of the $j^{\text {th }}$ vibrational mode, respectively. The $P, P_{j}$ and $P_{j j^{\prime}}$ values depend on the energy $E_{i f}$ and can easily be estimated using the fitting curves published in the Ref. [26].

\subsection{The Lagrange multiplier method for estimating $P, P_{j}$ and $P_{j j^{\prime}}$}

In this work we estimate $P, P_{j}$ and $P_{j j^{\prime}}$ values using Lagrange multipliers. In order to do that, we construct the Lagrange function

$$
L=\ln \left[\prod_{k=1}^{3 N-6}\left(\frac{e^{-y_{k}} y_{k}^{n_{k}}}{n_{k} !}\right)\right]-\lambda\left(\sum_{k=1}^{3 N-6} n_{k} \omega_{k}-E_{i f}\right)
$$

The equation system of the Lagrange function leads to an expression for each quantum number when the product $\left[\prod_{k=1}^{3 N-6}\left(\frac{e^{-y_{k}} y_{k}^{n_{k}}}{n_{k} !}\right)\right]$ reaches a maximum [21]:

$$
n_{k}=y_{k} \exp \left(-\omega_{k} \lambda\right)(14)
$$


where $\lambda$ is the Lagrange multiplier. The solution of equations $\left(\sum_{k=1}^{3 N-6} y_{k} \exp \left(-\omega_{k} \lambda\right) \omega_{k}\right)=E_{\text {if }}$ yields the $\lambda$ value. Lagrange's method for undetermined multipliers gives the maximum of the product $\left[\prod_{k=1}^{3 N-6}\left(\frac{e^{-y_{k}} y_{k}^{n_{k}}}{n_{k} !}\right)\right]$, which is the FranckCondon factor that fulfils the energy conservation condition $\left(\sum_{k=1}^{3 N-6} n_{k} \omega_{k}-E_{i f}\right)=0$. This approach also accounts for accepting modes with the $n_{k}>1$, which became the crucially important accepting modes when the energy difference between the initial and final states $\left(E_{i f}\right)$ is large.

\subsection{The anharmonic approximation}

\subsubsection{The $X-H$ bonds anharmonicity}

Previous studies showed that vibrational modes with large $y_{k}$ values $(>0.01)$ and energies larger than $1000 \mathrm{~cm}^{-1}$ provide large contributions to $\left[\prod_{k=1}^{3 N-6}\left(\frac{e^{-y_{k}} y_{k}^{n_{k}}}{n_{k} !}\right)\right]$ [26, 27]. Vibrational X-H bond stretching modes with energies of about 2000-3000 $\mathrm{cm}^{-1}$ have the largest contributions to $b_{j}$ and $t_{j}[26,27]$. In the harmonic approximation, the contributions to $b_{j}$ from the $\mathrm{X}-\mathrm{H}$ stretching modes are large when $n_{j}=1$, whereas it is negligible when $n_{j}>1$ due to the nature of the harmonic oscillator wave functions.

Anharmonic effects can be estimated by using the Morse oscillator, whose wave function is [38]

$$
\psi_{n}(R)=N_{n} \exp (-Z / 2) z^{b_{n} / 2} L_{n}^{b_{n}}(z)
$$

where $z=2 \beta \exp \left(-\alpha\left[R-R_{e}\right]\right), b_{n}=2 \beta-2 n-1, \beta=\frac{1}{\alpha} \sqrt{2 m D}$. The $D$ value is the dissociation energy, $\alpha$ is an anharmonicity constant, $m$ is the reduced mass, $R_{e}$ is the equilibrium distance, $N_{n}=\left(\frac{\alpha b_{n} n !}{\Gamma\left(b_{n}+n+1\right)}\right)^{1 / 2}, \quad L_{n}^{b_{n}}(z)$ is the n:th Laguerre 
polynomial, and $\Gamma\left(b_{n}+n+1\right)$ is the gamma function. Parameters $D$ and $\alpha$ can be obtained from the anharmonicity parameter $\chi$ and the energy $\omega$ as $D=\omega / 4 \chi$ and $\alpha=\sqrt{2 \omega \chi}$. The dissociation energy of the $\mathrm{X}-\mathrm{H}$ bonds is usually about $\sim 4.5 \mathrm{eV}$ and the typical vibrational energy $(\omega)$ of the $\mathrm{X}-\mathrm{H}$ bonds is $\sim 3300 \mathrm{~cm}^{-1}$, yielding a $\chi$ value of 0.02 [28]. Almost the same $\chi$ value was recently used for estimating anharmonic contributions to the $k_{I C}$ rate constant [25]. Using Eq. (15), one can derive an analytical expression for $b_{j}$ [39]

$$
b^{2}{ }_{j}=\frac{b_{n} b_{0} \Gamma(2 \beta-n)}{2 \beta^{2} \Gamma(2 \beta)} D
$$

The $b_{j}$ value in Eq. (16) decreases slower with increasing $n$ in comparison with the corresponding expression for $b_{j}$ in the harmonic approximation in Eq. (10). We use Eq. (16) to estimate the anharmonic effects. The energy of the Morse oscillator is $E_{j}=\omega_{j}\left(n_{j}+1 / 2\right)-\chi \omega_{j}\left(n_{j}+1 / 2\right)^{2}$, which is used in Eq. (2) and Eq. (3). The $t_{j}$ parameter can also be obtained by using the wave function of the Morse oscillator [40]:

$$
t^{2}{ }_{j}=\frac{(B-n) N \Gamma(2 B-n+1)}{2 n^{2}(2 B-n)^{2} \Gamma(2 B+1)}
$$

where $(B+1 / 2)^{2}=D$.

Using Eq. (16) and Eq. (17) yields significant contributions to $b_{j}$ and $t_{j}$ values even when $n_{j}>1$. This gives the opportunity to calculate also $P, P_{j}$ and $P_{j j^{\prime}}$ for molecules with smaller energy gap than $25000 \mathrm{~cm}^{-1}$, where anharmonic effects are less significant. The $b_{j}$ and $t_{j}$ parameters in the expressions for the IC rate constant have been calculated in the anharmonic approximation using Eq. (16) and Eq. (17) for only the strongly anharmonic X-H vibrational modes. $P, P_{j}$ and $P_{j j^{\prime}}$ were estimated using the fitting curves reported in Ref. [16]. $k_{I C}^{\text {anh-fit }}$ is then calculated using Eq. (4) and Eq. (5).

\subsubsection{The anharmonicity of vibrational modes with $\omega>1000 \mathrm{~cm}^{-1}$ and associated bond stretching}


The use of the Morse oscillator model is not very accurate for vibrational modes with energies in the range of $1000 \mathrm{~cm}^{-1}<\omega<3000 \mathrm{~cm}^{-1}$. However, the Franck-Condon factors can still be estimated by considering vibrational modes associated with bond stretching. This approach has been used by Yeganeh and Ratner [41], since the Franck-Condon factors $(<0 \mid n>)$ can be calculated analytically in this case [41, 42]:

$$
<0 \mid n>=\zeta^{N / 2}\left(\frac{2}{1+\zeta}\right)^{N-n} \frac{\Gamma(C-n)}{\Gamma(C-2 n+1)} \sqrt{\frac{(C-2 n) \Gamma(C-n+1)}{\Gamma(n+1) \Gamma(C)}}{ }_{2} F_{1}\left(-n, C-n ; C-2 n+1, \frac{2}{1+\zeta}\right)
$$

where ${ }_{2} F_{1}\left(-n, N-n ; N-2 n+1, \frac{2}{1+\zeta}\right)$ is hypergeometric function, $C=2 \sqrt{\frac{m D}{\alpha}}-1$ and $\zeta=\exp \left(-\alpha\left[R_{0}^{i}-R_{0}^{f}\right]\right)$, where $R_{0}^{i}-R_{0}^{f}$ is the difference in the equilibrium bond length of the initial and final states that can be obtained from the $y$ value of each mode. Eq. (18) holds when $\alpha=\alpha^{i}=\alpha^{f}$ or when the shape of the potential energy surface is very similar for the initial and final electronic states.

The method of Lagrange multipliers was employed in calculations of $k_{I C}$ using Eq. (16), Eq. (17) and Eq. (18) for $b_{j}, t_{j}$ and the Franck-Condon factors, respectively. We also used a $\chi$ value of 0.02 as in Ref. [25]. We use the notation $k_{I C}^{a n h}$ for the IC rate constants that were obtained using this approach. All $k_{I C}$ were calculated in the Herzberg-Teller approximation.

\subsection{The non-adiabatic interaction induced mixture between $S_{1}$ and $S_{2}$ for naphthalene and anthracene}

The mixture between $S_{1}$ and $S_{2}$ states induced by non-adiabatic interaction has recently been estimated for the tetraoxa[8]circulene and found to be very small [43], whereas the NACME is much larger for polyacenes [44]. Since the energy difference between $S_{1}$ and $S_{2}$ is small $\left(500-2500 \mathrm{~cm}^{-1}\right.$ ) [45], a high level of theory is required for estimating the NACME between these states, because the NACME can be of the same order as the energy gap. We used the BAGEL [46] software for 
calculating $\left\langle\varphi_{S_{2}}(\vec{r}, 5, \vec{R}) \frac{\partial \varphi_{S_{1}}(\vec{r}, 5, \vec{R})}{\partial R_{v q}}>\left.\right|_{R=R_{0}}\right.$. Finally $\left\langle\varphi\left(S_{2}\right)|\Lambda| \varphi\left(S_{1}\right)>\right.$ is estimated using $\left\langle\varphi_{S_{2}}(\vec{r}, \bar{s}, \vec{R}) \frac{\partial \varphi_{S_{1}}(\vec{r}, s, \vec{R})}{\partial R_{v q}}>\left.\right|_{\vec{R}=\vec{R}_{0}}\right.$ as well as Eq. (8) and Eq. (10) as in Ref. [43].

\section{Calculation details}

The molecular structure optimization, calculations of the second derivative of the potential energy surface (hessian) of the $S_{1}$ state, calculation of the first derivative of the potential energy surface (gradient) of the $S_{0}$ or $S_{2}$ states, calculations of the NACME between the $S_{1}$ and $S_{0}$ states, as well as calculations of spin-orbit coupling matrix elements (SOCME) between the $S_{1}$ state and an energetically lower triplet state were performed at the same level of theory as used in previous studies and described below [26, 27]. The molecular structures as well as the gradient and hessian calculations were performed for the lowest state at the density functional theory (DFT) and for the excited states - at the time dependent density functional theory (TDDFT) [47] level using the B3LYP [48] functional and the def2-TZVP [49] basis sets. The first-order NACMEs were calculated at the TDDFT level with the Turbomole code using perturbation theory [50, 51]. Spinorbit coupling matrix elements $\left\langle S_{1 \mid} H_{S O} \mid T_{i}\right\rangle$ between the $S_{1}$ state and the $\mathrm{i}^{\text {th }}$ triplet states $T_{i}$ being energetically below the $S_{1}$ state were calculated at the complete active space self-consistent field (CASSCF) level using Gamess-US [52, 53]. $<\frac{\varphi_{i}(\vec{r}, s, \vec{R}) \partial^{2} \varphi_{f}(\vec{r}, 5, \vec{R})}{\partial R_{v q} R_{v^{\prime} q^{\prime}}}>\left.\right|_{R=\vec{R}_{0}}$ and $\left(\left.\frac{\partial\left(H_{S O}^{i f}\right)}{\partial R_{v q}}\right|_{R=\vec{R}_{0}}\right)$ were calculated numerically using a three-point finite-difference approximation with a step length of $0.05 \AA$ along each Cartesian coordinate of the molecular structure.

Excitation energies calculated at the extended multi-configuration quasidegenerate perturbation theory of second order (XMC-QDPT2) [54] level were used as zeroth-order values. The XMC-QDPT2 calculations were performed using the Firefly software [55]. The initial guess MOs were obtained at the Hartree-Fock level of theory for $\mathrm{H}_{2}$ TPP. The 5 highest occupied MOs and the 5 lowest 
unoccupied MOs formed the active space in the CASSCF calculations, which were performed with state averaging over the four lowest electronic states. For the other molecules, we used the same active space as used in our previous works [26, 27].

In the calculation of $\left\langle\varphi\left(S_{2}\right)|\Lambda| \varphi\left(S_{1}\right)\right\rangle,\left.\quad\left\langle\varphi_{S_{2}}(\vec{r}, \vec{s}, \vec{R}) \frac{\partial \varphi_{S_{1}}(\vec{r}, 5, \vec{R})}{\partial R_{v q}}\right\rangle\right|_{\vec{R}=\bar{R}_{0}}$ was obtained at the XMC-CASPT2 level of theory using same active space and basis set as used in XMC-QPDT2 calculations on naphthalene and anthracene.

\section{Results and discussions}

\subsection{Naphthalene and anthracene}

Naphthalene fluoresces from the two lowest excited singlet states $\left(S_{1}\right.$ and $\left.S_{2}\right)$ [35, 44, 45], which suggests that $S_{1}$ and $S_{2}$ are strongly coupled by the nonadiabatic interaction. The same might hold for anthracene. The calculated $k_{I C}$ rate constants for naphthalene- $\mathrm{h}_{8}$ and for deuterated naphthalene- $\mathrm{d}_{8}$ are given in Table 1. The corresponding data for anthracene- $\mathrm{h}_{10}$ and anthracene- $\mathrm{d}_{10}$ are given in Table 2 .

The rate constants have been calculated using the harmonic and anharmonic approximations. Table 1 shows that very small $k_{I C}$ values are obtained when the harmonic approximation is used. The $k_{I C}^{\text {harm }}$ rate constant for the $\mathrm{S}_{1} \rightarrow \mathrm{S}_{0}$ transition of anthracene is two orders of magnitude smaller than $k_{I C}^{a n h}$, whereas the rest of the $k_{I C}^{\text {harm }}$ rate constants in Table 1 and 2 are several orders of magnitude smaller than the corresponding $k_{I C}^{a n h}$ rate constants.

The $k_{I C}^{a n h-f i t}$ and $k_{I C}^{a n h}$ rate constants for most transitions are of the same order of magnitude. The only exception is the rate constant for the $S_{2} \rightarrow S_{0}$ transition of anthracene- $d_{10}$. The $k_{I C}$ rate constant for the $S_{2} \rightarrow S_{0}$ transition of naphthalene is significantly larger than for the $S_{1} \rightarrow S_{0}$ transition, because the $S_{1} \rightarrow S_{0}$ transition possesses some accepting modes with small $y$ values. Naphthalene- $\mathrm{d}_{8}$ has $k_{I C}^{\text {anh-fit }}$ and $k_{I C}^{a n h}$ rate constants for the $\mathrm{S}_{1} \rightarrow \mathrm{S}_{0}$ transition that are two to three orders of magnitude smaller than for naphthalene- $h_{8}$. For the $S_{2} \rightarrow S_{0}$ transition, the naphthalene- $\mathrm{d}_{8}$ rate constants are one to two orders of magnitude smaller for than 
for naphthalene- $h_{8}$. The significantly faster IC process of naphthalene- $h_{8}$ is due to the $\mathrm{C}-\mathrm{H}$ accepting modes, whose vibrational energies of $3209 \mathrm{~cm}^{-1}$ and $3228 \mathrm{~cm}^{-1}$ are significantly larger than those for naphthalene- $\mathrm{d}_{8}$.

Table 1. The calculated accepting modes $\left(\omega\right.$ in $\left.\mathrm{cm}^{-1}\right)$ and the IC rate constants (in $\mathrm{s}^{-1}$ ) for the $\mathrm{S}_{1}\left(\mathrm{~B}_{3 \mathrm{u}}\right) \rightarrow \mathrm{S}_{0}\left(\mathrm{~A}_{\mathrm{g}}\right)$ and $\mathrm{S}_{2}\left(\mathrm{~B}_{2 \mathrm{u}}\right) \rightarrow \mathrm{S}_{0}\left(\mathrm{~A}_{\mathrm{g}}\right)$ transitions of naphthalene- $\mathrm{h}_{8}$ and naphthalene- $\mathrm{d}_{8}$. The irreducible representations of the electronic states are given in parenthesis. The Huang-Rhys factors $(y)$ and the irreducible representation (irrep) of the accepting modes are also given.

\begin{tabular}{|c|c|c|c|c|c|}
\hline Transition & $\begin{array}{c}\text { Accepting modes } \\
\omega(y), \text { irrep }\end{array}$ & $k_{I C}^{\text {harm- fit }}$ & $k_{I C}^{\text {harm }}$ & $k_{I C}^{a n h-f i t}$ & $k_{I C}^{a n h}$ \\
\hline \multicolumn{6}{|c|}{ naphthalene- $\mathrm{h}_{8}$} \\
\hline \multirow{4}{*}{$\mathrm{S}_{1}\left(\mathrm{~B}_{3 \mathrm{u}}\right) \rightarrow \mathrm{S}_{0}\left(\mathrm{~A}_{\mathrm{g}}\right)$} & 1417(0.18), $A_{g}$ & \multirow{4}{*}{$4 \cdot 10^{-8}$} & \multirow{4}{*}{$6 \cdot 10^{-14}$} & \multirow{4}{*}{$1 \cdot 10^{+1}$} & \multirow{4}{*}{$1 \cdot 10^{+1}$} \\
\hline & 1478(0.10), $\mathrm{B}_{1 \mathrm{~g}}$ & & & & \\
\hline & $3209\left(5 \cdot 10^{-4}\right), B_{1 g}$ & & & & \\
\hline & $3228\left(9 \cdot 10^{-4}\right), A_{g}$ & & & & \\
\hline \multirow{3}{*}{$\mathrm{S}_{2}\left(\mathrm{~B}_{2 \mathrm{u}}\right) \rightarrow \mathrm{S}_{0}\left(\mathrm{~A}_{\mathrm{g}}\right)$} & 1064(0.19), $A_{g}$ & \multirow{3}{*}{$2 \cdot 10^{-2}$} & \multirow{3}{*}{$1 \cdot 10^{-4}$} & \multirow{3}{*}{$8 \cdot 10^{+2}$} & \multirow{3}{*}{$2 \cdot 10^{+2}$} \\
\hline & 1414(0.56), $\mathrm{A}_{\mathrm{g}}$ & & & & \\
\hline & 1624(0.44), $\mathrm{B}_{1 \mathrm{~g}}$ & & & & \\
\hline \multicolumn{6}{|c|}{ naphthalene- $\mathrm{d}_{8}$} \\
\hline \multirow{3}{*}{$\mathrm{S}_{1}\left(\mathrm{~B}_{3 \mathrm{u}}\right) \rightarrow \mathrm{S}_{0}\left(\mathrm{~A}_{\mathrm{g}}\right)$} & 1410(0.31), $\mathrm{Ag}_{\mathrm{g}}$ & \multirow{3}{*}{$8 \cdot 10^{-9}$} & \multirow{3}{*}{$3 \cdot 10^{-16}$} & \multirow{3}{*}{$8 \cdot 10^{-2}$} & \multirow{3}{*}{$1 \cdot 10^{-2}$} \\
\hline & $2367\left(2 \cdot 10^{-4}\right), \mathrm{B}_{1 \mathrm{~g}}$ & & & & \\
\hline & $2379\left(5 \cdot 10^{-4}\right), A_{g}$ & & & & \\
\hline \multirow{3}{*}{$\mathrm{S}_{2}\left(\mathrm{~B}_{2 \mathrm{u}}\right) \rightarrow \mathrm{S}_{0}\left(\mathrm{~A}_{\mathrm{g}}\right)$} & $1313(0.27)$ & \multirow{3}{*}{$1 \cdot 10^{-2}$} & \multirow{3}{*}{$3 \cdot 10^{-5}$} & \multirow{3}{*}{$2 \cdot 10^{+1}$} & \multirow{3}{*}{$2 \cdot 10^{+1}$} \\
\hline & 1396(0.36), $A_{g}$ & & & & \\
\hline & 1560(0.59), $\mathrm{B}_{1 \mathrm{~g}}$ & & & & \\
\hline
\end{tabular}

Table 2. The calculated accepting modes $\left(\omega\right.$ in $\left.\mathrm{cm}^{-1}\right)$ and the IC rate constants (in $\mathrm{s}^{-1}$ ) for the $\mathrm{S}_{1}\left(\mathrm{~B}_{3 \mathrm{u}}\right) \rightarrow \mathrm{S}_{0}\left(\mathrm{~A}_{\mathrm{g}}\right)$ and $\mathrm{S}_{2}\left(\mathrm{~B}_{2 \mathrm{u}}\right) \rightarrow \mathrm{S}_{0}\left(\mathrm{~A}_{\mathrm{g}}\right)$ transitions of anthracene- $h_{10}$ and 
anthracene- $d_{10}$. The irreducible representations of the electronic states are given in parenthesis. The Huang-Rhys factors $(y)$ and the irreducible representation (irrep) of the accepting modes are also given.

\begin{tabular}{|c|c|c|c|c|c|}
\hline Transition & $\begin{array}{l}\text { Accepting modes } \\
\qquad \omega(y), \text { irrep }\end{array}$ & $k_{I C}^{\text {harm- fit }}$ & $k_{I C}^{\text {harm }}$ & $k_{I C}^{a n h-f i t}$ & $k_{I C}^{a n h}$ \\
\hline \multicolumn{6}{|c|}{ anthracene- $\mathrm{h}_{10}$} \\
\hline \multirow{3}{*}{$\mathrm{S}_{1}\left(\mathrm{~B}_{2 \mathrm{u}}\right) \rightarrow \mathrm{S}_{0}\left(\mathrm{~A}_{\mathrm{g}}\right)$} & 1431(0.52), $\mathrm{A}_{\mathrm{g}}$ & & & & \\
\hline & 1543(0.17), $\mathrm{B}_{1 \mathrm{~g}}$ & $2 \cdot 10^{+5}$ & $1 \cdot 10^{+4}$ & $6 \cdot 10^{+6}$ & $4 \cdot 10^{+6}$ \\
\hline & $1603(0.20), A_{g}$ & & & & \\
\hline \multirow{3}{*}{$\mathrm{S}_{2}\left(\mathrm{~B}_{3 \mathrm{u}}\right) \rightarrow \mathrm{S}_{0}\left(\mathrm{~A}_{\mathrm{g}}\right)$} & 1423(0.18), $A_{g}$ & & & & \\
\hline & 1521(0.10), $A_{g}$ & $3 \cdot 10^{-1}$ & $4 \cdot 10^{-7}$ & $3 \cdot 10^{+5}$ & $9 \cdot 10^{+4}$ \\
\hline & $3207\left(7 \cdot 10^{-4}\right), A_{g}$ & & & & \\
\hline \multicolumn{6}{|c|}{ anthracene- $\mathrm{d}_{10}$} \\
\hline \multirow{3}{*}{$\mathrm{S}_{1}\left(\mathrm{~B}_{2 \mathrm{u}}\right) \rightarrow \mathrm{S}_{0}\left(\mathrm{~A}_{\mathrm{g}}\right)$} & 1427(0.38), $\mathrm{A}_{\mathrm{g}}$ & & & & \\
\hline & $1471(0.24), \mathrm{B}_{1 \mathrm{~g}}$ & $6 \cdot 10^{+1}$ & $5 \cdot 10^{+3}$ & $2 \cdot 10^{+5}$ & $3 \cdot 10^{+5}$ \\
\hline & 1575(0.31), $A_{g}$ & & & & \\
\hline \multirow{3}{*}{$\mathrm{S}_{2}\left(\mathrm{~B}_{3 \mathrm{u}}\right) \rightarrow \mathrm{S}_{0}\left(\mathrm{~A}_{\mathrm{g}}\right)$} & 1384(0.03), $\mathrm{A}_{\mathrm{g}}$ & & & & \\
\hline & $1461(0.25), \mathrm{B}_{1 \mathrm{~g}}$ & $1 \cdot 10^{-1}$ & $4 \cdot 10^{-9}$ & $4 \cdot 10^{+2}$ & $5 \cdot 10^{-1}$ \\
\hline & $2375\left(2 \cdot 10^{-4}\right), A_{g}$ & & & & \\
\hline
\end{tabular}

The lowest excited state of anthracene belongs to the $B_{2 u}$ irreducible representation. Thus, the ${ }^{1} \mathrm{~B}_{2 u}$ and ${ }^{1} \mathrm{~B}_{3 \mathrm{u}}$ states of anthracene appear in the opposite order as compared to naphthalene. The calculated excitation energies are compared to experimental data in Table 3 . The calculations suggest that the $T_{1}$ and $T_{2}$ states of naphthalene and anthracene are energetically below the $S_{1}$ state.

The $k_{I C}$ rate constant of antracene is smaller for the $\mathrm{S}_{2} \rightarrow \mathrm{S}_{0}$ transition than for the $S_{1} \rightarrow S_{0}$ one regardless of the employed approximation. Deuteration decreases the $k_{I C}$ values for the $S_{2} \rightarrow S_{0}$ and the $S_{1} \rightarrow S_{0}$ transitions of anthracene as well as of naphthalene. The isotope effect on the $k_{I C}$ of the $\mathrm{S}_{1} \rightarrow \mathrm{S}_{0}$ transition of anthracene- $\mathrm{h}_{10}$ and anthracene- $\mathrm{d}_{10}$ is the same order of magnitude. The calculations also show that 
deuteration decreases the $k_{I C}$ values, which is expected to lead to an increase in the quantum yield of fluorescence $\left(\varphi_{f l}\right)$, if the ISC rate constants $\left(k_{I S C}\right)$ are the same for both isotopomers. (see Table 4). However, according to the experimental data, deuteration increases $\varphi_{f f}$ for naphthalene, but slightly decreases $\varphi_{f f}$ for anthracene $[45,56]$. The calculated rate constants in Table 4 shows that $k_{I C}$ of naphthalene is much smaller than $k_{r}\left(\mathrm{~S}_{1} \rightarrow \mathrm{S}_{0}\right)$ and $k_{r}\left(\mathrm{~S}_{2} \rightarrow \mathrm{S}_{0}\right)$ rates. Thus, the IC process has a very small effect on the quantum yield of naphthalene. The calculated $\varphi_{f l}$ yield for naphthalene of about 0.9 is also much larger than the experimental values of 0.24 and 0.42 for naphthalene- $h_{8}$ and naphthalene- $d_{8}$, respectively. The calculations provide too large quantum yields for naphthalene, and they also predict a too small isotope effect.

Table 3. Calculated excitation energies ( $E$ in $\mathrm{cm}^{-1}$ ), oscillator strengths (f), matrix elements of perturbation operators (in $\mathrm{cm}^{-1}$ ) for naphthalene- $\mathrm{h}_{8}$, naphthalene- $\mathrm{d}_{8}$, anthracene- $\mathrm{h}_{10}$ and anthracene- $\mathrm{d}_{10}$.

\begin{tabular}{ccc}
\hline Property & Naphthalene & Anthracene \\
\hline $\mathrm{E}\left(\mathrm{S}_{1}\right)$ & 33500 & 23390 \\
& $32050(\exp )[45]$ & 26610 (exp) [45] \\
\hline $\mathrm{E}\left(\mathrm{S}_{2}\right)$ & 36000 & 25890 \\
& $35000(\exp )[45]$ & 27900 (exp) [35] \\
\hline $\mathrm{E}\left(\mathrm{T}_{1}\right)$ & 21534 & 12647 \\
& $21250(\exp )[45]$ & 14900 (exp) [45] \\
\hline $\mathrm{E}\left(\mathrm{T}_{2}\right)$ & 32981 & 23128 \\
\hline $\mathrm{E}\left(\mathrm{T}_{3}\right)$ & 37000 & 29040 \\
\hline$<\varphi_{S_{1}}\left|\hat{H}_{S O}\right| \varphi_{T_{1}}>$ & 2.47 & 0.001 \\
\hline$<\varphi_{S_{2}}\left|\hat{H}_{S O}\right| \varphi_{T_{2}}>$ & 0.29 & 0.06 \\
\hline$f\left(\mathrm{~S}_{1} \rightarrow \mathrm{S}_{0}\right)$ & $1.6 \cdot 10^{-4}$ & $1.3 \cdot 10^{-4}$ \\
\hline$f\left(\mathrm{~S}_{2} \rightarrow \mathrm{S}_{0}\right)$ & 0.06 & Anthracene- $\mathrm{h}_{10}$ \\
\hline
\end{tabular}




$\begin{array}{ccc}<\varphi\left(S_{2}\right)|\Lambda| \varphi\left(S_{1}\right)> & 250 & 240 \\ & \text { Naphthalene-d } 8 & \text { Anthracene- } \mathrm{d}_{10} \\ <\varphi\left(S_{2}\right)|\Lambda| \varphi\left(S_{1}\right)> & 50 & 240\end{array}$

Table 4. The calculated rate constants (in $s^{-1}$ ) and the quantum yield of fluorescence $\left(\varphi_{f l}\right)$ for naphthalene- $\mathrm{h}_{8}$, naphthalene- $\mathrm{d}_{8}$, antracene- $\mathrm{h}_{10}$ and antracene$\mathrm{d}_{10}$.

\begin{tabular}{|c|c|c|}
\hline Parameter & Naphthalene- $\mathrm{h}_{8}$ & Naphthalene- $\mathrm{d}_{8}$ \\
\hline$k_{I C}^{a n h}\left(S_{2} \rightarrow S_{0}\right)$ & $2.0 \cdot 10^{2}$ & $2.0 \cdot 10^{1}$ \\
\hline$k_{I C}^{a n h}\left(\mathrm{~S}_{1} \rightarrow \mathrm{S}_{0}\right)$ & $1.0 \cdot 10^{1}$ & $1.0 \cdot 10^{-2}$ \\
\hline$k_{I S C}\left(\mathrm{~S}_{1} \rightarrow \mathrm{T}_{1}\right)$ & $1.0 \cdot 10^{4}$ & $1.0 \cdot 10^{4}$ \\
\hline$k_{I S C}\left(\mathrm{~S}_{1} \rightarrow \mathrm{T}_{2}\right)$ & 0 & 0 \\
\hline$k_{I S C}\left(\mathrm{~S}_{2} \rightarrow \mathrm{T}_{2}\right)$ & $2.0 \cdot 10^{6}$ & $2.0 \cdot 10^{6}$ \\
\hline$k_{r}\left(S_{1} \rightarrow S_{0}\right)$ & $1.2 \cdot 10^{5}$ & $1.2 \cdot 10^{5}$ \\
\hline$k_{r}\left(\mathrm{~S}_{2} \longrightarrow \mathrm{S}_{0}\right)$ & $5.0 \cdot 10^{7}$ & $5.0 \cdot 10^{7}$ \\
\hline$\varphi_{\text {fl }}$ & $>0.9$ & $>0.92$ \\
\hline$k_{r}^{*}\left(\mathrm{~S}_{1} \rightarrow \mathrm{S}_{0}\right)$ & $7.0 \cdot 10^{5}$ & $1.2 \cdot 10^{5}$ \\
\hline$k_{I S C} *\left(\mathrm{~S}_{1} \rightarrow \mathrm{T}_{2}\right)$ & $3.0 \cdot 10^{6}$ & $5.0 \cdot 10^{4}$ \\
\hline$\varphi_{f l}^{*}$ & 0.19 & 0.67 \\
\hline \multirow[t]{2}{*}{$\varphi_{f l}(\exp )[45]$} & 0.24 & 0.42 \\
\hline & Antracene- $\mathrm{h}_{10}$ & Antracene- $\mathrm{d}_{10}$ \\
\hline$k_{I C}^{a n h}\left(S_{1} \rightarrow S_{0}\right)$ & $6 \cdot 10^{6}$ & $3 \cdot 10^{5}$ \\
\hline$k_{I S C}\left(S_{1} \rightarrow T_{1}\right)$ & $4 \cdot 10^{3}$ & $4 \cdot 10^{3}$ \\
\hline$k_{I S C}\left(S_{1} \rightarrow T_{2}\right)$ & 0 & 0 \\
\hline$k_{I S C}\left(S_{2} \rightarrow T_{2}\right)$ & 2.0 & 2.0 \\
\hline$k_{r}\left(S_{1} \rightarrow S_{0}\right)$ & $2.0 \cdot 10^{7}$ & $2.0 \cdot 10^{7}$ \\
\hline$k_{r}\left(S_{2} \rightarrow S_{0}\right)$ & $1.0 \cdot 10^{5}$ & $1.0 \cdot 10^{5}$ \\
\hline$k_{r}^{*}\left(\mathrm{~S}_{1} \rightarrow \mathrm{S}_{0}\right)$ & $2.0 \cdot 10^{7}$ & $2.0 \cdot 10^{7}$ \\
\hline
\end{tabular}




\begin{tabular}{lcc}
\hline$k_{I S C}{ }^{*}\left(\mathrm{~S}_{1} \rightarrow \mathrm{T}_{2}\right)$ & 1 & 1 \\
\hline$\varphi_{f l}$ & 0.76 & 0.98 \\
\hline$\varphi_{f l}{ }^{*}$ & 0.18 & $0.33 ?$ \\
\hline$\varphi_{f l}(\exp )[45]$ & 0.67 & 0.10 \\
\hline
\end{tabular}

It has been suggested that there is a non-adiabatic coupling between the $\mathrm{S}_{1}$ and $S_{2}$ states for naphthalene [35, 44, 57], which significantly increases the ISC rate constant from the lowest singlet state to the second triplet state $k_{I S C} *\left(\mathrm{~S}_{1} \rightarrow \mathrm{T}_{2}\right)$. Here the asterisk $(*)$ denotes that $S_{1}$ is a mixture of the $S_{1}$ and $S_{2}$ states due to nonadiabatic coupling $\left(\varphi^{*}\left(S_{1}\right)=\varphi\left(S_{1}\right)+c_{12} \varphi\left(S_{2}\right)\right)$. The $c_{12}$ coefficient can be estimated using perturbation theory:

$$
c_{12}=\frac{<\varphi\left(S_{2}\right)|\Lambda| \varphi\left(S_{1}\right)>}{E\left(S_{2}\right)-E\left(S_{1}\right)}
$$

The calculated $\left\langle\varphi\left(S_{2}\right)|\Lambda| \varphi\left(S_{1}\right)\right\rangle$ values are $250 \mathrm{~cm}^{-1}$ and $50 \mathrm{~cm}^{-1}$ yielding $c_{12}$ coefficients of 0.1 and 0.02 for naphthalene- $\mathrm{h}_{8}$ and naphthalene- $\mathrm{d}_{8}$, respectively. Computational levels with the high accuracy show that these values are typical for NACME between $S_{1}$ and $S_{2}$ states, when the non-adiabatic coupling is significant $[58,59,60]$.

When the $c_{12}$ mixing coefficient is considered, the rate constant for the radiative transition from the mixed $\mathrm{S}_{1}$ state $k_{r} *\left(\mathrm{~S}_{1} \rightarrow \mathrm{S}_{0}\right)$ of naphthalene- $\mathrm{h}_{8}$ is $7.0 \cdot 10^{5} \mathrm{~s}^{-1}$ and $3.0 \cdot 10^{5} \mathrm{~s}^{-1}$ for naphthalene- $\mathrm{d}_{8}$. The ISC rate constant from the mixed $\mathrm{S}_{1}$ state $k_{I S C} *\left(\mathrm{~S}_{1} \rightarrow \mathrm{T}_{2}\right)$ is $3.0 \cdot 10^{6} \mathrm{~s}^{-1}$ for naphthalene- $\mathrm{h}_{8}$ and $5.0 \cdot 10^{4} \mathrm{~s}^{-1}$ for naphthalene- $\mathrm{d}_{8}$. The $k_{I S C}\left(\mathrm{~S}_{1} \rightarrow \mathrm{T}_{2}\right)$ vanishes without non-adiabatic mixing of $\mathrm{S}_{1}$ and $S_{2}$. For the mixed $S_{1}$ and $S_{2}$ state, we obtain quantum yields of fluorescence $\left(\varphi_{f l}{ }^{*}\right)$ of 0.19 and 0.67 for naphthalene- $h_{8}$ and naphthalene- $\mathrm{d}_{8}$, which agree rather well with the experimental values of 0.24 and 0.42 [45]. The calculations show the importance of considering non-adiabatic coupling between the $S_{1}$ and $S_{2}$ states when estimating the fluorescence quantum yield of naphthalene. 
For anthracene- $\mathrm{h}_{10}$, our calculations without considering the non-adiabatic interaction yields $\varphi_{f l}=0.87$, which agrees reasonably with the experimental value of 0.67 [45]. Thus, the IC process is the main non-radiative channel of the excited state, whereas the ISC process is much slower. The calculated $\left\langle\varphi\left(S_{2}\right)|\Lambda| \varphi\left(S_{1}\right)\right\rangle$ value of $240 \mathrm{~cm}^{-1}$ for anthracene- $\mathrm{h}_{10}$ and anthracene- $\mathrm{d}_{10}$ yielded $c_{12}=0.1$ for both isotopomers. Since $<\varphi_{S_{2}}\left|\hat{H}_{S O}\right| \varphi_{T_{2}}>$ is small, the non-adiabatic mixing does not significantly affect $k_{I S C}$. The rate constant of the radiative transition $k_{r}$ and the IC rate constant $k_{I C}$ are also unaffected by the mixing, because $\mathrm{k}_{\mathrm{r}}\left(\mathrm{S}_{1} \rightarrow \mathrm{S}_{0}\right)>>\mathrm{k}_{\mathrm{r}}\left(\mathrm{S}_{2} \rightarrow \mathrm{S}_{0}\right)$ and $k_{I C}\left(\mathrm{~S}_{1} \rightarrow \mathrm{S}_{0}\right)>>k_{I C}\left(\mathrm{~S}_{2} \rightarrow \mathrm{S}_{0}\right)$. The present calculations are not able to reproduce the experimentally observed anomalous deuteration effect of anthracene. The small energy difference between the $S_{1}$ and $T_{2}$ states may lead to a significant non-adiabatic coupling between them, whose strength may differ for the isotopomers. However, we are not aware of any software that could be employed to estimate this coupling.

Since the present algorithm gives the opportunity to accurately calculate $k_{I C}$ for molecules with $E_{i f}>25000 \mathrm{~cm}^{-1}$, we have also considered benzene as a test case. For benzene, we obtained $k_{I C}^{\text {anh-fit }}$ of $1.2 \cdot 10^{-1} \mathrm{~s}^{-1}$ and $k_{I C}^{\text {anh }}$ of $3.2 \cdot 10^{-2} \mathrm{~s}^{-1}$ for the $\mathrm{S}_{1} \rightarrow \mathrm{S}_{0}$ transition with an energy difference of $43500 \mathrm{~cm}^{-1}$ between the initial and final state. The accepting modes have vibrational energies of $3239 \mathrm{~cm}^{-1}$ and 1034 $\mathrm{cm}^{-1}$. The obtained results for benzene are in a good agreement with previously calculated values using a semi-empirical approach and with experimental data [35, $61]$.

\section{2 $\mathrm{H}_{2} \mathrm{P}$ and $\mathrm{H}_{2}$ TPP}

Free-base tetraphenylporphyrin $\left(\mathrm{H}_{2} \mathrm{TPP}\right)$ and free-base porphyrin $\left(\mathrm{H}_{2} \mathrm{P}\right)$ are interesting molecules for studies of photophysical properties, because deuteration of the two inner protons have significant effects on the photophysical properties of $\mathrm{H}_{2}$ TPP and almost no effect on the photophysical properties of $\mathrm{H}_{2} \mathrm{P}$ [45]. We have previously calculated rate constants for $\mathrm{H}_{2} \mathrm{P}$ and $\mathrm{H}_{2} \mathrm{TPP}$ using the different models 
and levels of theory [20, 26, 27], whereas we compute here contributions to their rate constants and to the quantum yield of fluorescence from the anharmonicity and deuteration perspectives. The obtained results are collected in Tables 5 and 6 . Some vibronic and spin-vibronic parameters are in good agreement with previous results $[62,63]$.

The harmonic and anharmonic approximations yield IC rate constants $k_{I C}^{\text {harm-fit }}, k_{I C}^{\text {anh-fit }}$ and $k_{I C}^{\text {anh }}$ that are of about same magnitude, whereas $k_{I C}^{\text {harm }}$ is much smaller. Anharmonicity is, in principle, not considered in the calculation of $k_{I C}^{\text {harm }}$ and $k_{I C}^{\text {harm-fit }}$. However, in the calculation of $k_{I C}^{\text {harm-fit }}$ the fitting curves with average $y$ values for the accepting modes consider to some extent the anharmonic effects, which are important for $\mathrm{H}_{2} \mathrm{P}$ due to the presence of a strongly anharmonic accepting mode with an energy of $3627 \mathrm{~cm}^{-1}$. Deuteration does not influence the $k_{I C}^{a n h-f i t}$ and $k_{I C}^{a n h}$ values even though the frequency of the accepting mode decreases. This is because the accepting mode of $\mathrm{D}_{2} \mathrm{P}$ (with an energy of $1364 \mathrm{~cm}^{-1}$ ) is upon deuteration excited with high quantum numbers, which compensates for the large energy shift of the second accepting mode from $3627 \mathrm{~cm}^{-1}$ to $2660 \mathrm{~cm}^{-1}$ for $\mathrm{D}_{2} \mathrm{P}$. The obtained results agree well with experimental data [45] and explain why the quantum yield of fluorescence $\left(\varphi_{f l}\right)$ is the same for $\mathrm{H}_{2} \mathrm{P}$ and $\mathrm{D}_{2} \mathrm{P}$. The IC process is the main deactivation channel of the $S_{1}$ state and the IC rate constant $\left(k_{I C}\right)$ is not affected by the deuteration.

The main deactivation channel of the $\mathrm{S}_{1}$ state of $\mathrm{H}_{2} \mathrm{TPP}$ is internal conversion. $\mathrm{H}_{2}$ TPP and $\mathrm{D}_{2}$ TPP have different accepting modes, whereas they are the same for $\mathrm{H}_{2} \mathrm{P}$ and $\mathrm{D}_{2} \mathrm{P}$. The vibrational mode corresponding to the accepting $\mathrm{N}$ $\mathrm{H}$ stretch at $3630 \mathrm{~cm}^{-1}$ in $\mathrm{H}_{2} \mathrm{TPP}$ is not an accepting mode of $\mathrm{D}_{2} \mathrm{TPP}$, which has instead several modes with lower frequencies that contributes to the calculated FC factor leading to a smaller $k_{I C}$ and $\varphi_{f l}$ than for $\mathrm{H}_{2}$ TPP.

Table 5. The calculated accepting modes $\left(\omega\right.$ in $\left.\mathrm{cm}^{-1}\right)$ and the IC rate constants (in $\mathrm{s}^{-1}$ ) for the $\mathrm{S}_{1} \rightarrow \mathrm{S}_{0}$ transition for the $\mathrm{H}_{2} \mathrm{P}, \mathrm{H}_{2} \mathrm{TPP}, \mathrm{D}_{2} \mathrm{P}$ and $\mathrm{D}_{2} \mathrm{TPP}$. The Huang-Rhys 
(HR) factors $(y)$ and the irreducible representation (irrep) of the accepting modes are also given.

\begin{tabular}{|c|c|c|c|c|c|}
\hline Molecule & $\begin{array}{l}\text { Accepting modes } \\
\omega, H R(y), \text { irrep }\end{array}$ & $k_{I C}^{\text {harm-fit }}$ & $k_{I C}^{\text {harm }}$ & $k_{I C}^{a n h-f i t}$ & $k_{I C}^{a n h}$ \\
\hline $\mathrm{H}_{2} \mathrm{P}$ & $\begin{array}{c}1364(0.04), \mathrm{B}_{1 \mathrm{~g}} \\
3627\left(1.6 \cdot 10^{-4}\right), \mathrm{A}_{\mathrm{g}}\end{array}$ & $8.0 \cdot 10^{7}$ & $1.0 \cdot 10^{1}$ & $4.0 \cdot 10^{8}$ & $8.0 \cdot 10^{7}$ \\
\hline $\mathrm{D}_{2} \mathrm{P}$ & $\begin{array}{l}1364(0.04), \mathrm{B}_{1 \mathrm{~g}} \\
2660(0.17), \mathrm{A}_{\mathrm{g}}\end{array}$ & $2.0 \cdot 10^{6}$ & $0.5 \cdot 10^{1}$ & $4.0 \cdot 10^{8}$ & $8.0 \cdot 10^{7}$ \\
\hline $\mathrm{H}_{2} \mathrm{TPP}$ & $\begin{array}{c}1558(0.02), \mathrm{A}_{1} \\
3630\left(3.3 \cdot 10^{-4}\right), \mathrm{A}_{1}\end{array}$ & $4.0 \cdot 10^{8}$ & $2.0 \cdot 10^{1}$ & $1.0 \cdot 10^{9}$ & $9.0 \cdot 10^{8}$ \\
\hline $\mathrm{D}_{2} \mathrm{TPP}$ & $\begin{array}{l}1258(0.03), A_{1} \\
1285(0.03), A_{1} \\
1386(0.02), A_{1} \\
1558(0.02), A_{1}\end{array}$ & $8.0 \cdot 10^{7}$ & $2.0 \cdot 10^{-1}$ & $9.0 \cdot 10^{7}$ & $2.0 \cdot 10^{7}$ \\
\hline
\end{tabular}

Table 6. Calculated excitation energies $\left(E\right.$ in $\left.\mathrm{cm}^{-1}\right)$, spin-orbit coupling matrix elements (in $\mathrm{cm}^{-1}$ ), rate constants (in $\mathrm{s}^{-1}$ ) and fluorescence quantum yield $\left(\varphi_{f}\right)$ for $\mathrm{H}_{2} \mathrm{P}, \mathrm{H}_{2} \mathrm{TPP}, \mathrm{D}_{2} \mathrm{P}$ and $\mathrm{D}_{2} \mathrm{TPP}$.

\begin{tabular}{ccccc}
\hline & $\mathrm{H}_{2} \mathrm{P}$ & $\mathrm{D}_{2} \mathrm{P}$ & $\mathrm{H}_{2} \mathrm{TPP}$ & $\mathrm{D}_{2} \mathrm{TPP}$ \\
\hline $\mathrm{E}\left(\mathrm{S}_{1}\right)$ & 17000 & 17000 & 16500 & 16500 \\
& 16210 (exp) [45] & & 15340 (exp) [45] & \\
\hline $\mathrm{E}\left(\mathrm{T}_{1}\right)$ & $\begin{array}{c}13000 \\
\text { 12580 (exp) [45] }\end{array}$ & 13000 & 11500 & 11500 \\
\hline $\mathrm{E}\left(\mathrm{T}_{2}\right)$ & 14517 & 14517 & 14040 (exp) [45] & \\
\hline$<\varphi_{S_{1}}\left|\hat{H}_{S O}\right| \varphi_{T_{1}}>$ & 1.6 & 1.6 & 1.3 & 1.3 \\
\hline$<\varphi_{S_{1}}\left|\hat{H}_{S O}\right| \varphi_{T_{2}}>$ & 0.0 & 0.0 & 0.0 & 0.0
\end{tabular}




\begin{tabular}{ccccc}
\hline$k_{I S C}\left(\mathrm{~S}_{1} \rightarrow \mathrm{T}_{1}\right)$ & $7.0 \cdot 10^{6}$ & $7.0 \cdot 10^{6}$ & $4.0 \cdot 10^{6}$ & $4.0 \cdot 10^{6}$ \\
\hline$k_{I S C}\left(\mathrm{~S}_{1} \rightarrow \mathrm{T}_{2}\right)$ & 0.0 & 0.0 & 0.0 & 0.0 \\
\hline$k_{r}\left(\mathrm{~S}_{1} \rightarrow \mathrm{S}_{0}\right)$ & \multicolumn{2}{c}{$5.0 \cdot 10^{6}$} & & \multicolumn{2}{c}{$2.0 \cdot 10^{7}$} & \\
\hline$k_{I C}^{\text {anh }}\left(\mathrm{S}_{1} \rightarrow \mathrm{S}_{0}\right)$ & $8.0 \cdot 10^{7}$ & $8.0 \cdot 10^{7}$ & $9.0 \cdot 10^{8}$ & $9.0 \cdot 10^{7}$ \\
\hline$\varphi_{f l}$ & 0.08 & 0.08 & 0.02 & 0.18 \\
\hline$\varphi_{f l}(\exp )[45]$ & 0.05 & 0.05 & 0.09 & 0.12 \\
\hline
\end{tabular}

\subsection{Tetraoxa[8]circulene and pyrromethene}

To check the accuracy of our algorithm, we have calculated $k_{I C}$ rate constants for tetraoxa[8]circulene (4B) and pyrromethene (PM567) and compared them to previously calculated IC rate constants that were obtained without considering anharmonic effects.

The obtained rate constants for 4B and PM567 are summarized in Table 7. For 4B, the anharmonic effects are small. The $k_{I C}^{\text {harm }}$ rate constant is a factor of 2-10 times smaller than $k_{I C}^{a n h}$ and $k_{I C}^{a n h-f i t}$, whereas $k_{I C}^{\text {harm-fit }}$ that considers some anharmonic effects is in closer agreement with the $k_{I C}^{a n h}$ and $k_{I C}^{a n h-f i t}$ rate constants. $k_{I C}^{a n h-f i t}$ is a factor of 4 larger than $k_{I C}^{\text {anh }}$. Thus, the harmonic and anharmonic approximations leads to similar rate constants, because the accepting modes for 4B do not involve any $\mathrm{X}-\mathrm{H}$ stretches.

One of the accepting modes of PM567 is the C-H stretch at $3062 \mathrm{~cm}^{-1}$. The $k_{I C}$ rate constant increases slightly when we consider anharmonic effects. However, the estimated the $\varphi_{f l}$ value of 0.76 is high, since the radiative transition with $k_{r}$ rate constant of $4 \cdot 10^{+7} \mathrm{~s}^{-1}$ is the main deactivation channel of the $\mathrm{S}_{1}$ state. 
Table 7. The calculated accepting modes $\left(\omega\right.$ in $\left.\mathrm{cm}^{-1}\right)$ and the IC rate constants (in $\mathrm{s}^{-1}$ ) for the $\mathrm{S}_{1} \rightarrow \mathrm{S}_{0}$ transition of $4 \mathrm{~B}$ and PM567. The Huang-Rhys (HR) factors $(y)$ and the irreducible representation (irrep) of the accepting modes are also given.

\begin{tabular}{|c|c|c|c|c|c|}
\hline Compound & $\begin{array}{c}\text { Accepting modes } \omega \text {, } \\
\text { HR }(y), \text { irrep }\end{array}$ & $k_{I C}^{\text {harm-fit }}$ & $k_{I C}^{\text {harm }}$ & $k_{I C}^{a n h-f i t}$ & $k_{I C}^{a n h}$ \\
\hline $4 \mathrm{~B}$ & $\begin{array}{l}1276(0.20), \mathrm{A}_{1 \mathrm{~g}} \\
1451(0.16), \mathrm{B}_{1 \mathrm{~g}} \\
1702(0.78), \mathrm{A}_{1 \mathrm{~g}}\end{array}$ & $7.0 \cdot 10^{6}$ & $4.0 \cdot 10^{6}$ & $4.0 \cdot 10^{7}$ & $1.0 \cdot 10^{7}$ \\
\hline PM567 & $\begin{array}{c}\text { 1255(0.06), } \mathrm{A}_{1} \\
3062\left(1.1 \cdot 10^{-3}\right), \mathrm{A}_{1}\end{array}$ & $1.0 \cdot 10^{6}$ & $3.0 \cdot 10^{4}$ & $9.0 \cdot 10^{6}$ & $7.0 \cdot 10^{6}$ \\
\hline
\end{tabular}

\section{Summary and discussion}

Computational methods for calculating rate constants of non-radiative transitions in the (Morse) anharmonic approximation have been developed and applied to naphthalene, anthracene, free-base porphyrin, free-base tetraphenylporphyrin, and their deuterated isotopomers, as well as to pyrometene and tetraoxa[8]circulene. The following conclusions can be drawn from the present calculations.

1. Anharmonic effects are important when calculating $\underline{k}_{I C}$ for transitions between electronic states that are energetically separated by more that 20000$25000 \mathrm{~cm}^{-1}$. Rate constants $k_{I C}^{a n h-f i t}$ and $k_{I C}^{a n h}$ obtained using anharmonic models are quite accurate.

2. Anharmonic effects are also important when the energy difference between the initial and final states is smaller than $20000-25000 \mathrm{~cm}^{-1}$, when the molecule contains an accepting $\mathrm{X}-\mathrm{H}$ stretching modes with a vibrational energy larger than $2000 \mathrm{~cm}^{-1}$. This is because the $\mathrm{X}-\mathrm{H}$ vibrations can be accurately described only when anharmonic effects are considered. In these cases, the 
anharmonic contributions to $k_{I C}$ can be estimated already using the $k_{I C}^{\text {harm-fit }}$ model described in Ref. [26].

3. Calculations of $k_{I C}^{\text {harm }}$ yielded accurate values for $k_{I C}$, when $\mathrm{E}_{\mathrm{if}}<20000$ $25000 \mathrm{~cm}^{-1}$ and there is at least one accepting mode with a sufficiently large Huang-Rhys factor $(y>0.1)$.

4. In the IC process of the studied molecules, the electronic excitation energy is converted into vibrational energy by exciting at least one of the $\mathrm{X}-\mathrm{H}$ modes $\left(b_{j}\right)$ and vibrational modes with large $y$ values. For larger energy differences between the initial and final states, the $\mathrm{X}-\mathrm{H}$ stretches are the main accepting vibrational modes, providing the main contribution to the $b_{j}$ and $P$ values.

Calculations of photophysical properties are still challenging. The accuracy of the electronic excitation energies obtained using modern state-of-the-art quantum chemistry methods is about $0.1 \mathrm{eV}$. Accurate calculations of the IC rate constants $\left(k_{I C}\right)$ for molecules with small energy differences $\left(E_{i f}\right)$ between the initial and final state $\left(10000 \mathrm{~cm}^{-1}<E_{i f}<20000 \mathrm{~cm}^{-1}\right)$ are difficult, because $k_{I C}$ depends strongly on $E_{i f}$. Explicit calculations of $k_{I C}$ require studies of complicated physical phenomena such as the Herzberg-Teller effect [26], anharmonic effects, which are studied here, and the Duschinsky rotation [64], which can also significantly affect the rate constants. Hybrid methods involving semi-empirical or even empirical approaches in the computational scheme can be necessary and also useful. Recently, Humeniuk et al. formulated some rules of thumb for non-radiative transition rates [25]. They found for example that the Duschinsky rotation can strongly increase the $k_{I C}$ value when the energy gap is large, whereas we here show that it is also very important to consider anharmonic effects in the calculation of $k_{I C}$. Duschinsky rotation is not accounted for in this work, which is the biggest shortcoming of our algorithm. Although recent studies showed that Duschinsky rotation can be important in calculations of $k_{I C}$ [22-24, 65-68], comparisons of calculated and experimental values for the rate constants and quantum yields suggest that the Duschinsky contribution is relatively small for the rigid molecules 
considered in this work. We plan though to implement Duschinsky rotation into our algorithm.

\section{Acknowledgments}

This work has been supported by the Academy of Finland through projects 325369 (RRV) and 314821 (DS). CSC - the Finnish IT Center for Science and the Finnish Grid and Cloud Infrastructure (persistent identifier urn:nbn:fi:research-infras2016072533) are acknowledged for computer time.

\section{References}

1) R. R. Valiev, R. M. Gadirov, K. M. Degtyarenko, D. V. Grigoryev, R. T. Nasubullin, G. V. Baryshnikov, B. F. Minaev, S. K. Pedersen, M. Pittelkow, Chem. Phys. Lett., 2019, 732, 136667.

2) R. M. Gadirov, R. R. Valiev, L. G. Samsonova, K. M. Degtyarenko, N. V. Izmailova, A. V. Odod, S. S. Krasnikova, I. K. Yakuschenko, T. N. Kopylova, Chem. Phys. Lett., 2019, 717, 53-58.

3) G. V. Baryshnikov, R. R. Valiev, N. N. Karaush, V. A. Minaeva, A. N. Sinelnikov, S. K. Pedersen, M. Pittelkow, B. F. Minaev, H. Ågren, Phys. Chem. Chem. Phys., 2016, 18, 28040-28051.

4) R. R. Valiev, E. N. Telminov, T. A. Solodova, E. N. Ponyavina, R. M. Gadirov, G. V. Maier, T. N. Kopylova, Chem. Phys. Lett., 2013, 588, 184-187.

5) R. R. Valiev, A. N. Sinelnikov, Y. V. Aksenova, R. T. Kuznetsova, M. B. Berezin, A. S. Semeikin, V. N. Cherepanov, Spectrochim. Acta A, 2014, 117, 323329

6) B. F. Minaev, R. R. Valiev, E. N. Nikonova, R. M. Gadirov, T. A. Solodova, T.

N. Kopylova, E. N. Tel’minov, J. Phys. Chem. A, 2015, 119, 1948-1956.

7) G. Chen, W. Shao, R. R. Valiev, T. Y. Ohulchanskyy, G. S. He, H. Ågren, P. N. Prasad, Adv. Opt. Mater., 2016, 4, 1760-1766.

8) C.-K. Lim, M. Maldonado, R. Zalesny. R. Valiev, H. Ågren, A. S. L. Gomes, J. J. R. Pachter, P. N. Prasad. Adv. Funct. Mater., 2020, 30, 1909375. 
9) X. Zhang, W. Chen, X. Xie, Y. Li, D. Chen, Z. Chao, C. Liu, H. Ma, Y. Liu, H. Ju, Angew. Chem. Int. Ed., 2019, 58, 12117-12122.

10) S. Monro, K. L. Colón, H. Yin, J. Roque III, P. Konda, S. Gujar, R. P. Thummel, L. Lilge, C. G. Cameron, S. A. McFarland, Chem. Rev., 2019, 119, 797-828.

11) J.-H. Liang, Y. Zheng, X.-W. Wu, C.-P. Tan, L.-N. Ji, Z.-W. Mao, Adv. Sci., 2019, 7, 1901992.

12) B. Liu, S. Monro, Z. Li, M. A. Jabed, D. Ramirez, C. G. Cameron, K. Colón, J. Roque, S. Kilina, J. Tian, S. A. McFarland, W. Sun, ACS Appl. Bio. Mater., 2019, 2, 2964-2977.

13) R. R. Valiev, A. A. Berezhnoy, I. S. Gritsenko, B. S. Merzlikin, V. N. Cherepanov, T. Kurtén, C. Wöhler, Astron. Astrophys., 2020, 633, A39.

14) R. R. Valiev, T. Kurtén. Is Either Direct Photolysis or Photocatalyzed H-shift of Peroxyl Radicals A Competitive Pathways in the Troposphere? RSOS (in press)

15) B. Bohn, F. Rohrer, T. Brauers, A. Wahner, Atmos. Chem. Phys., 2005, 5, $493-$ 503 ,

16) R. R. Valiev, G. Hasan, V.-T. Salo, J. Kubečka, T. Kurtén, J. Phys. Chem. A, 2019, 123, 30, 6596-6604.

17) F. Bianchi, T. Kurten, M. Riva, C. Mohr, M. P. Rissanen, P. Roldin, T. Berndt, J. D. Crounse, P. O. Wennberg, T. F. Mentel, J. Wildt, H. Junninen, T. Jokinen, M. Kulmala, D. R. Worsnop, J. A. Thornton, N. Donahue, H. G. Kjaergaard, M. Ehn, Aerosol. Chem. Rev., 2019, 119, 3472-3509.

18) G. Baryshnikov, B. Minaev, H. Ågren., Chem. Rev., 2017, 117, 6500-6537

19) T. J. Penfold, E. Gindensperger, C. Daniel, C. M. Marian, Chem. Rev., 2018, 118, 6975-7025.

20) R. R. Valiev, V. N. Cherepanov, V. Ya. Artyukhov, D. Sundholm, Phys. Chem. Chem. Phys., 2012, 14, 11508-11517.

21) E. S. Medvedev, V. I. Osherov, Radiationless Transitions in Polyatomic Molecules. Springer-Verlag, Berlin, 1995. 
22) Y. Niu, Q. Peng, C. Deng, X. Gao, Z. Shuai., J. Phys. Chem. A, 2010, 114, 30, 7817-7831.

23) Y. Niu, Q. Peng, Z. Shuai, Science in China Series B: Chemistry, 2008, 51, 1153-1158.

24) Q. Peng, Y. Niu, Q. Shi, X. Gao, Z. Shuai, J. Chem. Theory Comput., 2013, 9, 1132-1143.

25) A. Humeniuk, M. Bužančić, J. Hoche, J. Cerezo, R. Mitrić, F. Santoro, V. Bonačić-Koutecký, J. Chem. Phys., 2020, 152, 054107.

26) R. R. Valiev, V. N. Cherepanov, R. T. Nasibullin, D. Sundholm, T. Kurtén, Phys. Chem. Chem. Phys., 2019, 21, 18495-18500.

27) R. R. Valiev, V. N. Cherepanov, G. V. Baryshnikov, D. Sundholm, Phys. Chem. Chem. Phys., 2018, 20, 6121-6133.

28) V.G. Plotnikov, Int. J. Quant. Chem., 1979, 16, 527-541.

29) M. Bixon, J. Jortner, J. Chem. Phys., 1968, 48, 715-726.

30) Y. Liu, M. Lin, Y. Zhao, J. Phys. Chem. A, 2017, 121, 1145-1152.

31) V. Pomogaev, S. Chiodo, K. Ruud, R. Kuznetsova, P. Avramov, J. Phys. Chem. C, 2020, 124, 11100-11109.

32) J. Greiner, R. R. Valiev, D. Sundholm, Phys. Chem. Chem. Phys., 2020, 22, 10314-10321.

33) B.I. Makshantsev, Spectrosc. Lett., 1972, 5, 1-6.

34) B.I. Makshantsev, Spectrosc. Lett., 1972, 5, 7-12.

35) N. Nijegorodov, V. Ramachandran, D. P. Winkoun, Spectrochim. Acta, Part A, 1997, 53, 1813-1824.

36) B. S. Neporent, Pure Appl. Chem., 1974, 37, 111-146.

37) K. Rebane, P. Saari, J. Luminescence, 1976, 12/13, 23-31.

38) P. Morse, Phys. Rev., 1929, 34, 57-64.

39) M. Bancewicz, J. Phys. A: Math. Gen., 1998. 31, 3461-3467.

40) E. F de Lima, J. E M Hornos, J. Phys. B: At. Mol. Opt. Phys., 2005, 38, 815825.

41) S. Yeganeh, M. A. Ratner, J. Chem. Phys., 2006, 124, 044108. 
42) J. C. López, V. A. L. Rivera, Yu. F. Smirnov, A. Frank, Int. J. Quantum Chem., 2002, 88, 280-295.

43) R. R. Valiev, Chem. Phys. Lett., 2020, 738, 136914.

44) G. V. Mayer, Photophysical Processes and Generation Abilities of Aromatic Molecules, Tomsk University, Tomsk, 1992, 265 pp, in Russian.

45) V. L. Ermolaev, Opt. Spectrosc., 2016, 121, 567-584.

46) BAGEL, Brilliantly Advanced General Electronic-structure Library. http://www.nubakery.org under the GNU General Public License.

47) M. Casida, in Recent Advances in Density Functional Methods, World Scientific, Singapore, 1999, Part I, pp. 155-192

48) C. Lee, W. Yang, R. G. Parr, Phys. Rev. B: Condens. Matter Mater. Phys., 1988, 37, 785-789

49) F. Weigend, R. Ahlrichs, Phys. Chem. Chem. Phys., 2005, 7, 3297-3305

50) R. Send, F. Furche, J. Chem. Phys., 2010, 132, 044107.

51) R. Ahlrichs, M. Bär, M. Häser, H. Horn, C. Kölmel, Chem. Phys. Lett., 1989, 162, $165-169$

52) M. W. Schmidt, K. K. Baldridge, J. A. Boatz, S. T. Elbert, M. S. Gordon, J. H. Jensen, S. Koseki, N. Matsunaga, K. A., S. Su, T. L. Windus, M. Dupuis, J. A. Montgomery, J. Comput. Chem., 2006, 14, 1347-1363

53) D. G. Fedorov, S. Koseki, M. W. Schmidt, M. S. Gordon, Int. Rev. Phys. Chem., 2003, 22, 551-592

54) A. A. Granovsky, J. Chem. Phys., 2011, 134, 214113.

55) A. A. Granovsky, Firefly version 8.0.0, www http://classic.chem.msu.su/gran/firefly/index.html

56) A. Amirav, M. Sonnenschein, J. Jortner, Chem. Phys. Lett., 1983, 100, 488-493.

57) Y. F. Pedash, O. V. Prezhdo, S. I. Kotelevskiy, V. V. Prezhdo, THEOCHEM, 2002, 585, 49-59

58) J. Gibson, T. J. Penfold, Phys. Chem. Chem. Phys., 2017, 19, 8428-8434.

59) M. K. Etherington, J. Gibson, H. F. Higginbotham, T. J. Penfold, A. P. Monkman, Nat. Commun., 2016, 7, 13680. 
60) J. Gibson, A. P. Monkman, T. J. Penfold, Chem. Phys. Chem. 2016, 17, 29562961.

61) V. Ya. Artyukhov, A. I. Galeeva, G. V. Maier, V. V. Ponomarev, Optics and Spectroscopy., 1997, 82, 520-523.

62) B. Minaev, Y.H. Wang, C.K. Wang, Y. Luo, H. Ågren. Spectrochim. Acta, A. 2006, 65, 308-323.

63) B. F. Minaev, H. Ågren. Chem. Phys., 2005, 315, 215-239.

64) F. Duschinsky, Acta Physicochim. URSS, 1937, 7, 551-566.

65) U. Werner, R. Mitrić, V. Bonačić-Koutecký, J. Chem. Phys. 2010, 132, 174301.

66) R. Islampour, M. Miralinaghi, J. Phys. Chem. A, 2009, 113, 2340-2349.

67) R. Ianconescu, J. Tatchen, E. Pollak, J. Chem. Phys. 2013, 139, 154311.

68) S. Banerjee, A. Baiardi, J. Bloino, V. Barone, J. Chem. Theory Comput., 2016, 12, 774-786. 